\title{
Peripheral nerve gap repair facilitated by a dynamic tension device
}

\author{
David S McDonald MD ${ }^{1}$, Michael SG Bell MD FRCSC ${ }^{2}$
}

\begin{abstract}
DS McDonald, MSG Bell. Peripheral nerve gap repair facilitated by a dynamic tension device. Can J Plast Surg 2010;18(1):e17-e19.

End-to-end neurorrhaphy remains the gold standard for transected nerve repair. However, the current dogma is that to be successful, nerve repairs must be tension free. Therefore, nerve gaps are most commonly repaired with grafts. While there is evidence that nerves can regenerate successfully after initial approximation under a tensile force, the amount of tension that deters regeneration of human nerves remains unclear. The present paper describes a case in which a favourable functional outcome was obtained following repair of a median nerve gap that was reduced by a dynamic tension device. The case provides some evidence that modest separations between stumps can be overcome by dynamic tension, enabling primary end-to-end repair of nerve gaps.
\end{abstract}

Key Words: Dynamic; Nerve; Regeneration; Repair; Tension; Transection

\section{La réparation de la brèche d'un nerf périphérique facilitée par un dispositif de tension dynamique}

\begin{abstract}
La neurorraphie terminoterminale demeure la référence pour réparer un nerf sectionné. Cependant, selon la norme actuelle, pour réussir, les réparations nerveuses doivent être dénuées de tension. C'est pourquoi la brèche d'un nerf est surtout réparée par une greffe. Certaines données probantes indiquent que les nerfs peuvent se régénérer après l'approximation initiale d'une force de tension, mais on ne connaît pas vraiment la quantité de tension qui prévient la régénération des nerfs humains. Le présent article décrit un cas à l'issue fonctionnelle favorable après la réparation de la brèche d'un nerf médian, réduite par un dispositif de tension dynamique. Ce cas démontre qu'il est possible de corriger de modestes séparations entre les moignons par une tension dynamique, qui permet la réparation terminoterminale primaire de brèches de nerfs.
\end{abstract}

$\mathrm{N}$ erve gaps encountered in the repair of transected peripheral nerves can occur from the destruction of nerve segments at the time of injury, from surgical trimming of abnormal or damaged nerve segments, from immediate recoil of intrinsic elastic elements, or from progressive retraction of the nerve stumps that occurs when reconstruction is delayed. Repair of these gaps can be a challenge.

There are currently three basic methods to repair a transected nerve: end-to-end direct coaptation, nerve grafting and tubulization repair. End-to-end neurorrhaphy remains the gold standard because it has traditionally provided the best functional outcome. However, modern surgical dogma dictates that functional recovery relies on a tension-free repair. For this reason, surgeons are often reluctant to primarily close even modest nerve gaps.

Tension has been found to hamper regeneration, possibly by promoting scar formation and adhesions $(1,2)$. Tension also impairs blood supply to the nerves $(3,4)$. In particular, Flores et al (3) found that an induced 8\% elongation causes a $46 \%$ decrease in perfusion, thereby potentially limiting regeneration of transected peripheral nerves. Although both explanations seem logical, some important questions remain to be answered. For example, nerves are clearly capable of some degree of adaptation in length that allows for motion at the joints without subsequent nerve damage (2). The limits of such longitudinal compliance are not known. Additionally, the span of nerve gaps that can be closed without extensive mobilization of proximal and distal stumps is not clearly defined because the amount of tension that deters nerve regeneration is not known. Because uncertainty concerning these issues remains, nerve grafting has become the preferred method to avoid tension in the reconstruction of nerve gaps.

While nerve grafts are an attractive solution to the nerve gap, they are to be used judiciously after consideration of several issues. For example, nerve graft tissue may form a physical barrier to appropriate target innervation by misaligning regenerating neurites and targeting Schwann cell tubules (5). Even if the diameter of the nerve graft closely matches the diameter of the nerve to be repaired, variations in fascicular structure of the nerves prevent accurate realignment of transected axons. Also, for an axon to grow across a graft, it must overcome two suture lines (at both the entry and exit of the graft). Each suture line can be a barrier to the regenerating axons. Specifically, a fibrous tissue reaction contributing to scar formation at suture lines has been shown to impede regeneration (6). Finally, the often minimized issue of donor site morbidity can be significant $(7,8)$.

An article by Sunderland et al (9) provided evidence that nerves can withstand a certain degree of stretching before negatively affecting regeneration. In their rat sciatic nerve model, gaps of up to $6 \mathrm{~mm}$ could be closed primarily with subsequent anatomical and functional recovery, similar to that obtained with a gap of $0 \mathrm{~mm}$. Only when the nerves were stretched to overcome a $9 \mathrm{~mm}$ gap (corresponding to approximately $0.56 \mathrm{~N}$ of tensile force) was there a demonstrable negative impact on regeneration. Sunderland et al (9) hypothesized the existence of a 'tension threshold' and proposed that nerves can indeed be stretched without detriment up to an intrinsically determined point. In a cynomolgus monkey model, Hentz et al (10) showed that small nerve gaps $(1.5 \mathrm{~cm})$ repaired under tension with epineurial sutures showed better

${ }^{1}$ University of Manitoba, Winnipeg, Manitoba; ${ }^{2}$ Department of Surgery, Division of Plastic Surgery, The Ottawa Hospital - Civic Campus, Ottawa, Ontario

Correspondence: Dr Michael SG Bell, 402-1919 Riverside Drive, Ottawa, Ontario K1H 1A2. Telephone 613-739-5424, fax 613-739-7168, e-mail msgbell@cyberus.ca 


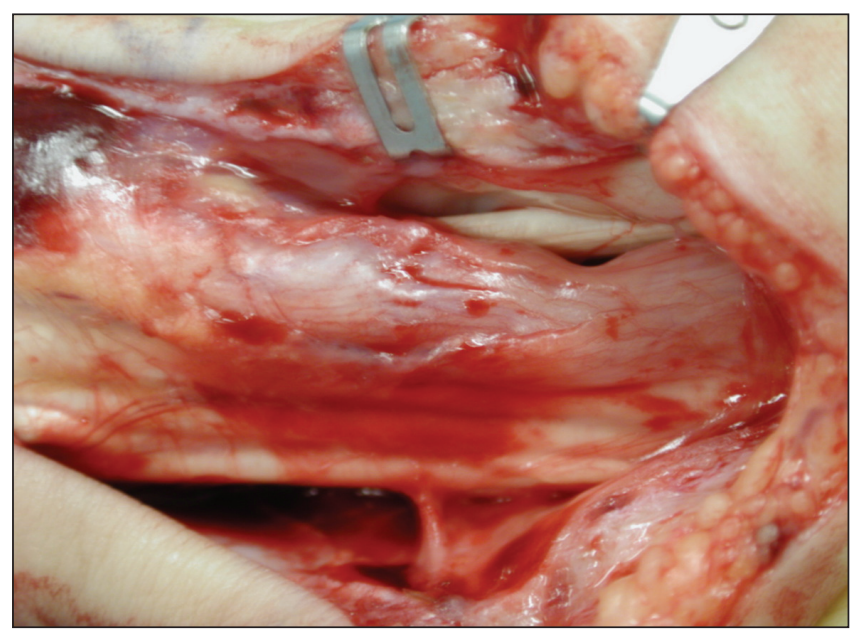

Figure 1) Intraneural neuroma

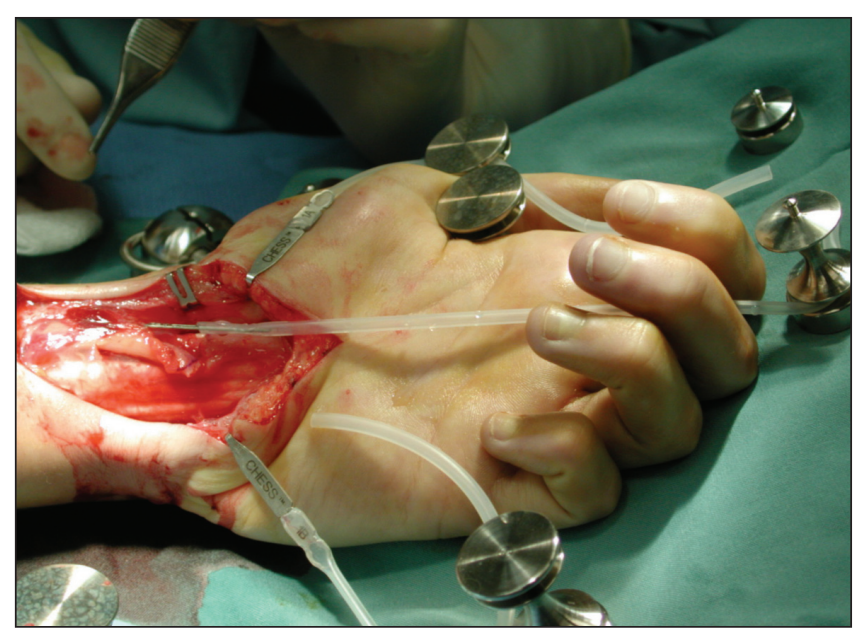

Figure 2) Dynamic traction applied

recovery than autografted gaps, both electrophysiologically and anatomically.

The present paper describes a case in which a nerve gap lesion was successfully repaired by end-to-end neurorrhaphy after reduction with a dynamic tension device. The case provides some evidence that modest gaps can be overcome by prestretching the nerve.

\section{CASE PRESENTATION}

A 25-year-old woman was involved in a motor vehicle accident, in which she sustained a somewhat blunt transverse laceration to her left wrist just proximal to the wrist crease. Unfortunately, the true gravity of her injury was initially missed. She presented six weeks after this injury with total loss of sensation in the distribution of the median nerve and completely absent abductor pollicis brevis (APB) function as measured by a sensitive, quantitative force gauge (11). She had Tinel's sign approximately $1 \mathrm{~cm}$ proximal to the transverse laceration.

The patient was taken to the operating room, where her left lower leg was prepped in addition to her left wrist, anticipating a possible sural nerve graft. After applying a tourniquet, the wrist wound was explored under a microscope. A neuroma-in-continuity of the median nerve measuring $1.1 \mathrm{~cm}$

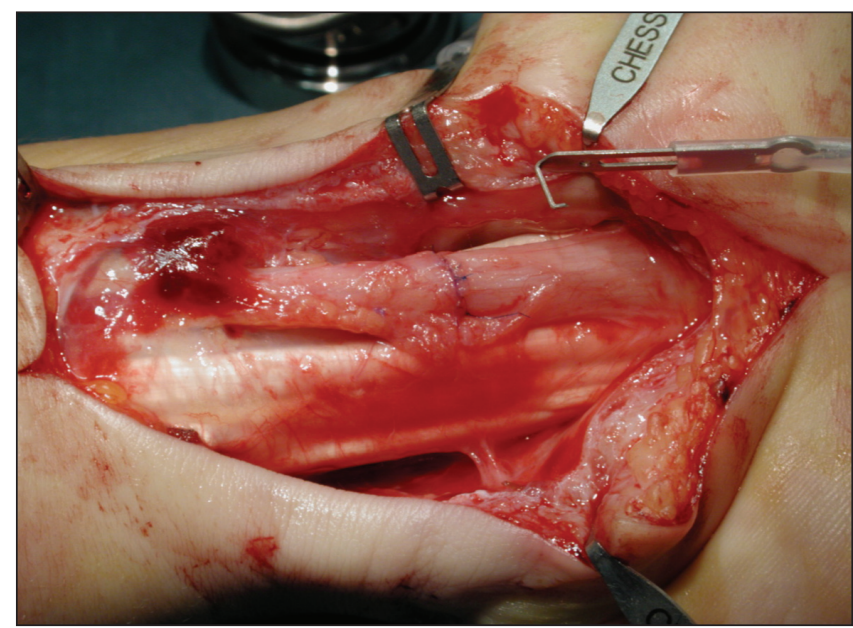

Figure 3) Microsuture line

was identified and excised (Figure 1). Serial sections of the remaining nerve stumps were made until a normal fascicular pattern was evident, resulting in a total excision of approximately $2 \mathrm{~cm}$ of the patient's median nerve. After excision of the neuroma, the nerve stumps retracted leaving a gap of approximately $4 \mathrm{~cm}$. The fascicular pattern was carefully marked on both the proximal and distal ends to facilitate accurate realignment. An initial attempt to appose the retracted stumps with the wrist in a neutral position resulted in tension, which traditionally would have resulted in a nerve graft repair.

To prevent further retraction of the proximal nerve stump in the present case, a new Micronerve Hook (CHESS Surgery System, Canica Design Inc, Canada) was used. This small hook was inserted into the epineurium $2 \mathrm{~cm}$ proximal to the nerve stump, and was attached to the end of a silastic elastomer and fixed by a rare earth magnet to the steel hand plate of the CHESS Surgery System. Over a period of approximately $20 \mathrm{~min}$, the nerve gradually (and surprisingly) stretched so that there was, in fact, overlap of the stumps (Figure 2). When the nerve hook was removed, the nerve stumps remained in this stretched position, allowing for a tensionfree primary repair with the wrist in a neutral position. This was performed with four epineural sutures of 7-0 prolene and eight additional 9-0 nylon sutures. The nerve was aligned in accordance with the fascicular pattern, and it was believed that the quality and tension of the nerve repair were equivalent to the quality and tension of a repair performed under 'ideal' circumstances of zero gap (Figure 3 ).

A dorsal wrist splint was applied to maintain the wrist in flexion for four weeks. Thereafter, the patient's hand was gradually mobilized and, over the next 11 months, protective sensation returned to the distribution of the median nerve. Motor function also showed progressive recovery. At four months postoperatively, the APB strength still could not be measured, although it was noted by observation that there was some occurrence of slight muscle contraction. By 11 months, the APB strength in the affected left hand was measured at $0.5 \mathrm{~kg}$ compared with $1.8 \mathrm{~kg}$ on the right side. At 16 months postoperatively, the uninjured right side remained stable at $1.8 \mathrm{~kg}$ while the left hand showed further improvement in APB strength, testing repeatedly at approximately $1.0 \mathrm{~kg}$ (Figure 4). 
At present, the patient has good protective sensation. Her hand function is very good, with an ability to achieve thumb to small finger opposition, and with good functional chuck pinch and key pinch.

The authors believe that the functional recovery of this nerve injury has been comparable with that expected following a primary end-to-end nerve coaptation repair. To overcome the size of gap encountered in the present case, the authors would have typically chosen to perform a nerve graft. However, with dynamic stretching of the nerve that occurred over a period of approximately $20 \mathrm{~min}$, the repair was in fact performed under ideal circumstances, virtually tension free.

\section{DISCUSSION}

Nerves are intrinsically elastic structures that are always under some tension and undergo varying degrees of stretching (ie, with joint movement). For example, it has been estimated that the median nerve stretches up to $10 \mathrm{~cm}$ during flexion and extension of the elbow (2). It would, therefore, seem reasonable to expect a nerve to be able to withstand some stretching during modest gap repairs.

While the work of Sunderland et al (9) clearly challenges the view that tension deters nerve regeneration, it is still unclear how $6 \mathrm{~mm}$ in a rat sciatic nerve might translate into applicable human nerve measurements. Hentz et al (10) proposed that the gap of $1.5 \mathrm{~cm}$ closed primarily in their primate model would likely compare with $3 \mathrm{~cm}$ to $4 \mathrm{~cm}$ in a human; however, this has not been confirmed. Clearly, experimental work will need to be undertaken to ascertain this relationship.

Conventional attempts at closing nerve gaps have seen the use of large traction sutures placed rather traumatically into the proximal and distal stumps in an effort to reef the ends together.

\section{REFERENCES}

1. Millesi H. Reappraisal of nerve repair. Surg Clin North Am 1981;61:321-40.

2. Millesi $\mathrm{H}$. The nerve gap: Theory and clinical practice. Hand Clin 1986;2:651-63.

3. Flores AJ, Lavernia CJ, Owens PW. Anatomy and physiology of peripheral nerve injury and repair. Am J Orthop 2000;29:167-73.

4. Lundborg G. Intraneural microcirculation. Orthop Clin North Am 1988;19:1-12

5. De Medinacelli L, Rawlings RR. Is it possible to predict the outcome of peripheral nerve injuries? A probability model based on prospects for regenerating neurites. Biosystems 1987;20:243-58.

6. Hentz VR, Rosen JM, Xiao SJ, McGill KC, Abraham G.

A comparison of suture and tubulization nerve repair techniques in a primate. J Hand Surg Am 1991;16:251-61.

7. Brandt J, Dahlin LB, Lundborg G. Autologous tendons used as grafts for bridging peripheral nerve defects. J Hand Surg Br 1999;24B:284-90.

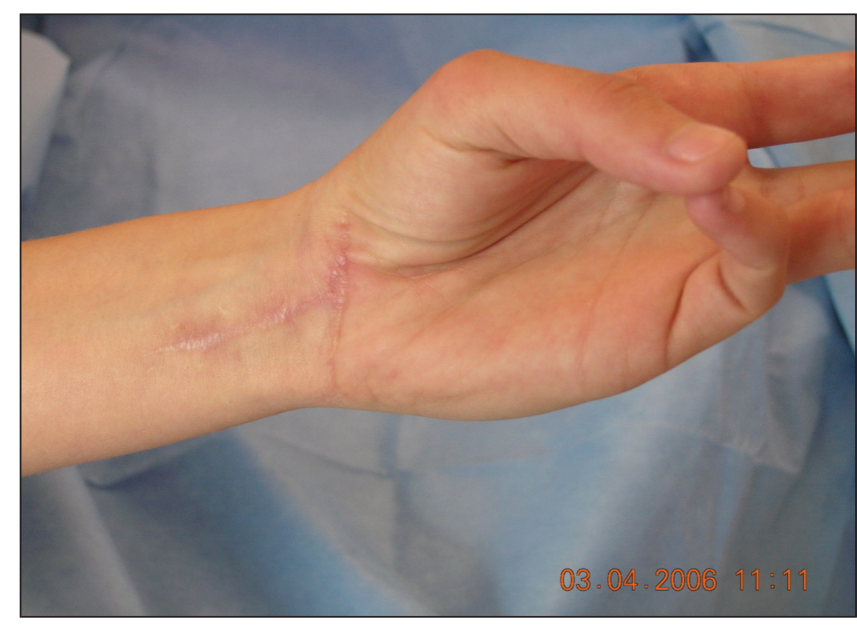

Figure 4) Muscle recovery at 15 months (abductor pollicis brevis strength $1.0 \mathrm{~kg}$ versus $1.8 \mathrm{~kg}$ on right hand)

Nerve-approximating clamps (Van Beek Nerve Approximator Clamps, Accurate Surgical \& Scientific Instruments, USA) have also been used to provide serial static pressure to close nerve gaps and align stumps (12). Both of these techniques use a large amount of static force over a short time. In contrast, the Dynamic Micronerve Hook described uses small amounts of dynamic force applied over a relatively long period of time to bring retracted tissues together.

The functional return observed in the present case raises many questions regarding the current standards of managing nerve gaps created by intraneural neuromas and slightly retracted nerves. These can only be answered over time with further laboratory studies and good randomized clinical trials.

8. IJpma FFA, Nicolai JPA, Meek MF. Sural nerve donor-site morbidity: Thirty-four years of follow-up. Ann Plast Surg 2006;57:391-5

9. Sunderland IR, Brenner MJ, Singham J, Rickman SR, Hunter DA, Mackinnon SE. Effect of tension on nerve regeneration in rat sciatic nerve transection model. Ann Plast Surg 2004;53:382-7.

10. Hentz VR, Rosen JM, Xiao SJ, McGill KC, Abraham G. The nerve gap dilemma: A comparison of nerves repaired end to end under tension with nerve grafts in a primate model. J Hand Surg Am 1993;18A:417-25.

11. Bigelow E, Bell M. Carpal tunnel syndrome: A new objective evaluation technique. Can J Plast Surg 1998;6:99-103.

12. Van Beek AL, Zook EG. A nerve approximating device. Plast Reconstr Surg 1980;66:143-7. 